\title{
Phenotypic features of central sensitization
}

\author{
David A. Williams
}

Department of Anesthesiology, University of Michigan Health System, Ann Arbor, Michigan

\section{Correspondence}

David A. Williams, Department of Anesthesiology, University of Michigan Health System, 24 Frank Lloyd Wright Drive, PO Box 385, Lobby M, Ann Arbor, MI 48106.

Email: daveawms@umich.edu

\section{Funding information}

AR070600 University of Michigan CORT (NIH/NIAMS).

\begin{abstract}
The current manuscript reviews approaches for phenotyping central sensitization (CS). The manuscript covers the concept of diagnostic phenotyping, use of endophenotypes, biomarkers, and symptom clusters. Specifically, the components of CS that include general sensory sensitivity (assessed by quantitative sensory testing) and a symptom cluster denoting sleep difficulties, pain, affect, cognitive difficulties, and low energy (S.P.A.C.E.). Each of the assessment domains are described with reference to CS and their presence in chronic overlapping pain conditions (COPCS)-conditions likely influenced by CS. Chronic overlapping pain conditions likely represent clinical diagnostic phenotypes of CS. Components of CS can also be assessed using QST or self-report instruments designed to assess single elements of CS or more general composite indices.

\section{KEYWORDS}

central sensitization, chronic overlapping pain conditions, mental load, phenotyping, sensory hypersensitivity, unwellness
\end{abstract}

\section{1 | INTRODUCTION}

Central sensitization (CS) is a multifaceted spinal and cortical process by which the central nervous system (CNS) amplifies nociceptive sensory stimuli, which may then be perceived as experiences of unpleasantness, threat, or pain. This special issue has combined decades of research to shed light on the mechanisms of this process. While 
CS requires multiple processes to occur, the clinical phenotype is an individual who presents with unpleasant sensory experiences disproportionate to any observable peripheral cause. The International Association for the Study of Pain (I.A.S.P.) defines CS as "Increased responsiveness of nociceptive neurons in the central nervous system to their normal or subthreshold afferent input" (IASP, 2015). CS can be inferred clinically from the presence of allodynia and hyperalgesia. In addition to these markers derived from quantitative sensory testing (QST), there may be other indices suggestive of CS (Nijs et al., 2014). This article provides additional insights into the clinical characteristics of individuals suspected of experiencing CS.

\section{2 | CLINICAL CHARACTERIZATION: PHENOTYPING, BIOMARKERS, AND SYMPTOMS}

A phenotype refers to the composite of one's observable traits or characteristics resulting from an interaction between an individual's genetic code, in combination with influences from the environment. In practice, clinical phenotypes are often just the diagnostic label for a given disease (e.g., Diagnositic and Statistical Manual for Mental Disorders [DSM] or International Classification of Diseases [ICD] code). Such clinical phenotypes tend to be defined by expert consensus and often incorporate multiple symptoms rather than reflecting discrete or unique pathology. Due to their breadth, diagnostic labels are often less than optimal phenotypes for genetic studies (Hall \& Smoller, 2010; Tsuang, 2001).

An alternative to using diagnostic labels as phenotypes is the use of more genetically informative alternative phenotypes, of which there are three types: (a) component phenotypes, (b) intermediate phenotypes, and (c) covariates (Szatmari et al., 2007). The component phenotype refers to a cardinal symptom or dimension of a disorder (e.g., hallucinations in schizophrenia, (Szatmari et al., 2007) widespread pain in fibromyalgia (Wolfe et al., 2010)). To be genetically informative, the component symptom should only be found in affected individuals. Intermediate phenotypes occur with greater intensity in affected family members than unaffected family members, but family members (affected or unaffected) should exhibit the trait more than in the general population. Of note, given that the trait occurs in both affected and unaffected family members, it cannot be a defining feature of the disorder, like the component phenotype. An intermediate phenotype is analogous to the concept of an "endophenotype" and can include biochemical, physiological, behavioral, cognitive, and self-reported forms of data. Examples of intermediate phenotypes include oculomotor function in schizophrenia (Gottesman \& Gould, 2003) and affective vulnerability in Temporomandibular Joint Disorders (Diatchenko, Nackley, Slade, Fillingim, \& Maixner, 2006). Finally, covariates act as moderators defining subgroups in which the linkage between genetics and the disorder may be stronger or weaker depending upon the covariate (e.g., groups with early life exposure to pain may be more vulnerable to developing fibromyalgia; (Low \& Schweinhardt, 2012)).

While the intent of identifying phenotypes is to help link observable characteristics to genetic markers, much of what has been called phenotyping has never actually been validated as having clear links to genetics (e.g., the literature on initial smoking risk factors; (Audrain-McGovern, Nigg, \& Perkins, 2009). Thus, using the term "phenotyping" may simply reflect a clinical feature that appears to be related to a condition but fails to demonstrate genetic linkage. Such clinical features may simply be medical symptoms associated with a diagnostic label or mechanism.

Often confused with phenotypes is the concept of a biomarker. Biomarkers can also be used to characterize a disorder and can be defined broadly as any interaction between a biological system and potential hazard that can be reproducibly measured (Strimbu \& Tavel, 2010). Biomarkers can be functional, physiological, biochemical, or molecular, but unlike phenotypes, may or may not have genetic influences and can tend to be state-dependent phenomena (Beauchaine \& Constantino, 2017). Blood pressure is a good example of a biomarker associated with the clinical phenomena of hypertension. 
Central sensitization, as defined by Woolf (Latremoliere \& Woolf, 2009; Woolf, 2011), has been translated into clinical diagnostic criteria by Nijs et al. (2014). Summarizing this approach for identifying CS, the pain complaint cannot be due to neuropathic pain (e.g., lesions, neuropathy, diseases of the nervous system) or described as such (e.g., shooting, burning pricking pain) and not due to nociceptive or inflammatory processes (e.g., pain proportional to injury or identifiable inflammatory processes). In addition, there needs to be evidence of widespread pain (i.e., not just the localized complaint), hypersensitivity to sensory processes in general (e.g., sensitivity to light, sound, touch, odors, etc.), and symptoms that are both products and contributors to the construct of "mental load" (e.g., sleep problems, pain intensity, affective lability, cognitive difficulties, and lack of energy/fatigue). See Table 1 for a summary of Nils et al.'s approach to clinically identifying patients experiencing CS. Based upon this conceptualization, the clinical characterization of CS appears to involve a combination of candidate phenotypes, biomarkers, and medical symptoms.

\section{3 | CHRONIC OVERLAPPING PAIN CONDITIONS (C.O.P.C.S): THE DIAGNOSTIC PHENOTYPES OF CS}

Of the 100 million individuals who suffer with chronic pain, a sizable percentage, mostly women, will suffer from multiple chronic pain conditions simultaneously (i.e., COPCs; (Committee on Advancing Pain Research, Education, \& Institute of, 2011; Maixner, Fillingim, Williams, Smith, \& Slade, 2016; Veasley et al., 2015)). The concept of coexisting pain conditions has been recognized by the National Institutes of Health (NIH) as a set of disorders that may share a common mechanism (e.g., CS) and includes, but should not be limited to, temporomandibular disorders (TMD), fibromyalgia (FM), irritable bowel syndrome (IBS), vulvodynia (VVD), myalgic encephalomyelitis/chronic fatigue syndrome (ME/CFS), interstitial cystitis/painful bladder syndrome (IC/PBS), endometriosis (ENDO), chronic tension-type headache (CTTH), migraine headache (MI), and chronic lower back pain (CLBP). Thus, despite being diagnosed with each condition separately, the problem may not be with the specific presenting complaint but with a common mechanism that amplifies peripheral input from multiple bodily locations so as to produce centrally augmented pain (i.e., CS; (Clauw, 2014; Maixner et al., 2016)). For example, a patient with both IBS and TMD would likely be seen by a Gastroenterologist focused upon identifying pathology in the gut as well as a Dentist focused upon identifying pathology in the jaw. In practice, neither practitioner would be likely to suspect a common

TAB LE 1 Criteria for the clinical classification of central sensitization pain (Nijs et al., 2014)

$\begin{array}{lll}\text { Step } 1 & \text { Rule out neuropathic pain } & \begin{array}{c}\text { No history or identification of lesion or disease of the } \\ \text { nervous system }\end{array} \\ & \begin{array}{l}\text { Pain is not neuroanatomically logical } \\ \text { Pain is not described as burning, shooting, or pricking }\end{array} \\ \text { Step } 2 & \text { Pule out nociceptive pain } & \begin{array}{l}\text { Pain will be disproportionate to the extent of injury or } \\ \text { pathology }\end{array} \\ \text { Step } 3 & \begin{array}{l}\text { At least one of the following (if } \\ \text { Steps 1-3 are positive then CS } \\ \text { present) }\end{array} & \begin{array}{l}\text { Bilateral symmetrical pain pattern } \\ \text { Pain varying in anatomical location (i.e., traveling) or } \\ \text { large neuroanatomically illogical distributions }\end{array} \\ & \begin{array}{l}\text { Widespread pain in all four quadrants of the body } \\ \text { Step } 4\end{array} & \begin{array}{l}\text { Allodynia/hyperalgesia outside the reported primary site } \\ \text { of pain }\end{array} \\ & \begin{array}{l}\text { General hypersensitivity to } \\ \text { sensory stimuli (If Steps 1-2, } \\ \text { and } 4 \text { are positive then CS } \\ \text { present) }\end{array} & \begin{array}{l}\text { heat, electrical stimulation, light, sounds, weather, food, } \\ \text { stress, emotions, mental load. Can be assessed as a } \\ \text { score of } \geq 40 \text { on the CSI }\end{array}\end{array}$


underlying mechanism such as aberrant central pain processing. Instead, treatment would likely focus on "correcting" the peripheral or anatomical source of each pain complaint-an approach which is not likely to address the common underlying etiology of the conditions (Maixner et al., 2016; Williams \& Clauw, 2009). Given the COPCs are suspected of being diagnostic manifestations of CS, comparisons of COPCs with other forms of chronic pain may provide valuable insights into pragmatic clinical indices of CS.

\section{1 | Generalized sensory hypersensitivity}

One feature of CS that has been explored in the context of COPCs is the concept of generalized sensory hypersensitivity. For example, in FM, the cardinal symptom is widespread pain and tenderness upon touch. Upon further assessment, however, such individuals also tend to report hypersensitivity to other sensory modalities including auditory, olfactory, and visual stimuli (Geisser et al., 2008; Wilbarger \& Cook, 2011). This generalized sensory hypersensitivity has been documented in other COPCs such as migraine (Friedman \& De ver Dye, 2009; Goadsby et al., 2017; Main, Dowson, \& Gross, 1997), IBS (Berman et al., 2002; Blomhoff, Jacobsen, Spetalen, Dahm, \& Malt, 2000), and TMD (Hollins et al., 2009). Generalized sensory hypersensitivity has been associated with activation of a cortical network composed of the anterior cingulate, the insula, and the prefrontal cortex (Pujol et al., 2014). The function of this network is not unique to pain but appears to have the more general function of extracting salient sensory stimuli for subsequent higher order neural processing (lannetti \& Mouraux, 2010; Schmidt-Wilcke et al., 2014). The means by which this network determines salience appears to be based upon the following factors: (a) stimulus novelty, (b) sharpness of the stimulus onset, (c) stimulus deviance, and (d) stimulus intensity in contrast to less relevant background stimuli (Legrain, lannetti, Plaghki, \& Mouraux, 2011).

While clinically it would be difficult to assess and document these cortical events using imaging techniques, there are methods from quantitative sensory testing (QST) and self-report inventories that can assist in documenting the presence of generalized sensory hypersensitivity in clinical settings.

Quantitative Sensory Testing (QST) assesses psychophysiological mechanisms thought to be associated with CS. Such mechanisms include sensitivity to nonpainful stimuli (e.g., allodynia), generalized increased pain in response to previously painful stimuli (e.g., hyperalgesia), indices of centrally mediated pain facilitation (e.g., temporal summation), and indices of centrally mediated pathology in pain inhibitory mechanisms (e.g., conditioned pain modulation).

Allodynia refers to the experience of pain resulting from traditionally nonpainful stimuli. For example, someone with CS might experience pain in response to a light stroke of a feather or brush. Often the standardized assessment of allodynia utilizes monofilaments or exposure to light brush strokes (Maracle et al., 2017). Many of the COPCs exhibit allodynia including fibromyalgia (Eken et al., 2017), TMD (Ernberg, Hedenberg-Magnusson, Alstergren, Lundeberg, \& Kopp, 1999), migraine (Tietjen et al., 2009), and chronic fatigue (Yasui et al., 2014). In general, allodynia may be a by-product of the CS concept of "mental load" (Crettaz et al., 2013).

Hyperalgesia is typically assessed by identifying pain thresholds in individuals using standardized stimuli facilitated by pressure devices such as algometers, ischemic cuff algometry, or computerized mechanical testing devices such as the Multimodal Automated Sensory Testing (MAST) System (AMI, Ann Arbor, MI https://www. arbormedicalinnovations.com/) (Harte et al., 2013, 2016; Henry et al., 2014; Schrepf et al., 2015; Wasserman et al., 2015)-an automated QST platform. In patients presenting with a localized pain complaint, increased pain sensitivity at remote or unaffected body areas is strongly suggestive of central pain mechanisms and is a common feature of the COPCs (Berkley, Cason, Jacobs, Bradshaw, \& Wood, 2001; Chaves et al., 2016; Janig, 2015; Jayaram et al., 2015; McAllister, McGinty, Resuehr, \& Berkley, 2009; Scheich et al., 2017; Toriyama, Horiuchi, \& Hongo, 2017).

Temporal Summation and its associated metric of wind-up, is a marker of CNS facilitation of pain perception. Technically, it is an increase in pain perception following repeated painful stimulation at a constant stimulus intensity. For example, a $256 \mathrm{mN}$ pinprick stimulus can be applied once to the forearm or hand, followed by a train of 10 
identical stimuli $(1 \mathrm{~Hz})$. Comparison of the original single pinprick stimuli with the ratings after repeated stimulation is used to calculate a wind-up ratio (WUR). A WUR > 1 indicates temporal summation (Rolke et al., 2006). The presence of wind-up has long been proposed as a feature of central sensitization (Nijs et al., 2014; Woolf, 2011) and has been identified in many COPCs (e.g., FM (Price et al., 2002), including TMD (Maixner, Fillingim, Sigurdsson, Kincaid, \& Silva, 1998), LBP (Tesarz, Eich, Treede, \& Gerhardt, 2016), endometriosis (Napadow et al., 2012), and IBS (Zhou, Price, Callam, Woodruff, \& Verne, 2011)).

Quantitative sensory testing may not be feasible in all clinical settings, so self-reported sensory hypersensitivity may also be used to document this phenomena. One such measure is the Sensory Hypersensitivity Scale (SHS; Dixon et al., 2016). The SHS is a 25 -item measure that assesses both general hypersensitivity as well as modalityspecific sensitivity (e.g., touch taste, auditory). This instrument demonstrated modest associations with three modalities of QST (i.e., heat threshold and tolerance, and cold tolerance), and weaker relationships with psychiatric constructs such as depressive symptoms and anxiety in a mixed chronic pain and healthy sample. Individuals with FM scored higher on this measure than did individuals with low back pain, osteoarthritis, or healthy controls, thus supporting its construct validity as a measure of sensory hypersensitivity (a component of CS).

\section{2 | Symptom clusters}

Patients and clinicians may perceive symptoms as arising independently when in fact, they may be interacting synergistically (Aktas, Walsh, \& Rybicki, 2010). Such an observation has given rise to the study of symptom clusters (Miaskowski, Dodd, \& Lee, 2004). A common symptom cluster observed within the context of primary care is composed of sleep disturbance, pain, anxiety, depression, and low energy/fatigue (SPADE) (Davis, Kroenke, Monahan, Kean, \& Stump, 2016). In this study of 250 patients with musculoskeletal pain, only $9.6 \%$ were monosymptomatic, while $20 \%$ of the sample had all five symptoms in the SPADE cluster. Clearly most of the sample was polysymptomatic. The study went on to demonstrate significant associations between the number of symptoms and greater functional impairment within the domains of general health, physical and mental functioning, social functioning, and health-related disability.

A similar symptom cluster has attracted attention within the oncology literature. This cluster, composed of three of the SPADE elements, includes pain, sleep insufficiency, and fatigue. Being one of the most common combined symptom presentations, this cluster is similarly associated with poorer outcomes and poorer functional status in oncology patients (Dodd, Miaskowski, \& Paul, 2001) and is thought to be associated with an underlying inflammatory mechanism (Cleeland et al., 2003).

Potentially related to the symptom cluster seen in oncology, "Sickness Behavior" is a construct translated from the animal literature describing a coordinated set of symptoms elicited by proinflammatory cytokines, tumor necrosis factor alpha, interleukin-6, and interleukin 1-beta (Shattuck \& Muehlenbein, 2016). The effect in animals of such activation is to alter the normal homeostatic condition, so as to cause fever, lose appetite, and lose weight. It also causes symptoms similar to those defined above, including sleep disturbance, fatigue, altered affect, and increased pain sensitivity (Tizard, 2008). Early on, it was observed that sick animals tended to exhibit these symptoms, and as such, it was thought to represent weakness or illness. Later studies suggested that rather than being a by-product of illness, these symptoms might represent an adaptive physiological response designed to enhance the animal's chances of recovery and survival. For example, increased pain sensitivity and fatigue could limit hunting and mating, thus conserving energy to fight infection or recover from injury. Studies in humans have identified the same sickness behavior symptom cluster with the addition of cognitive disturbances (e.g., memory) (Shattuck $\&$ Muehlenbein, 2016), again with the potential role of adaptive functioning to conserve resources.

Whether inflammation is required (as in the sickness behavior model) or not (as in the SPADE and some cancer examples), there is remarkable similarity in these symptom clusters suggestive of a common mechanism representing a state of "general unwellness." A symptom cluster commonly identified in COPCs includes Sleep disturbance, Pain of a widespread distribution, Affective perturbation, Cognitive disturbance, and Energy deficit 
(fatigue). The acronym S.P.A.C.E. can be used to remember the elements of this cluster. S.P.A.C.E. is very similar to SPADE except that it adds the construct of cognitive difficulties given the importance of this symptom to human sickness behavior model. In a recent longitudinal study using environmental momentary assessment of dyscognition, pain, mood, and fatigue, a lagged relationship was identified among symptoms, suggesting that dyscognition may actually precede or trigger the rest of the symptom cluster (Kratz, Murphy, \& Braley, 2017). These results underscore the importance of including cognitive problems in a symptom cluster for CS. Thus, the presence of S.P.A.C.E. may reflect a state of general unwellness. Perhaps this perturbed state is perceived as threatening and gives rise to the sensory hypervigilance described above. Clinically, S.P.A.C.E. can be assessed using a number of instruments which will be reviewed next.

\subsection{1 | Sleep}

Disturbances in sleep are common in the context of chronic pain and can manifest as problems with falling asleep, staying asleep, and early morning awakening. Brief instruments for assessing sleep quality and disturbances can be obtained through the Patient-Reported Outcomes Measurement Information System (PROMIS) administration and information website, AssessmentCenter ${ }_{\mathrm{TM}}$ (Cella et al., 2010). Other measures of sleep disturbances that have been used in the assessment of COPCs include the Medical Outcomes Study (MOS) sleep scale (Allen, Kosinski, Hill-Zabala, \& Calloway, 2009) and the Pittsburg Sleep Quality Index (PSQI; (Buysse, Reynolds, Monk, Berman, \& Kupfer, 1989)). Sleep duration may not have to be disturbed to impact wellness. It is not uncommon for some patients to report getting a sufficient quantity of sleep only to experience that sleep as unrefreshing or nonrestorative. Nonrestorative sleep has been associated with reduced short-wave sleep and abnormal $\alpha$-rhythms, suggestive of wakefulness during non-REM (rapid eye movement) sleep (Choy, 2015). This latter from of sleep problem may be the more relevant in the context of COPCs and CS (Calhoun, Ford, Finkel, Kahn, \& Mann, 2006; Choy, 2015; Tu, Heitkemper, Jarrett, \& Buchanan, 2017). A measure that captures some of these nonrestorative features of sleep is the PROMIS measure of sleep-related impairment (Yu et al., 2011).

\subsection{2 | Clinical pain}

The most common approach to assessing pain is through the use of visual analog scales (VAS), numeric rating scales (NRS) or a "faces" approach (by choosing from a range of smiling and frowning faces) (Jensen \& Karoly, 2011). Pain intensity, however, is not unique to CS, and pain intensity alone may not differentiate individuals with COPCs from individuals with other forms of chronic pain. For example, in a study comparing pain characteristics of patients with fibromyalgia versus rheumatoid arthritis, pain intensity did not differ on a 0-100 VAS (i.e., 61 vs. 59, respectively) (Leavitt, Katz, Golden, Glickman, \& Layfer, 1986). Despite pain intensity failing to distinguish these conditions, other aspects of pain did appear distinguishing, such as the quality of pain, its distribution (e.g., how widespread it was), and its temporality (e.g., constant vs. intermittent). Thus in the context COPCs and CS, assessing these other aspects may be important (Spiegel et al., 2010). Perhaps most important for CS is the concept of widespread pain distribution, which is often captured using a body map. Many of the standardized pain assessment tools include a body map, along with measures of pain intensity, such as the Brief Pain Inventory (BPI; (Cleeland, 2009)) or qualitative descriptors such as the McGill Pain Questionnaire (MPQ; (Melzack, 1975)) and the painDETECT.(Freynhagen, Baron, Gockel, \& Tolle, 2006) In a study of over 400 individuals with urologic chronic pelvic pain syndrome (UCPPS), only $25 \%$ indicated pain on a body map as being localized to the pelvic region. In this study, $75 \%$ reported pain beyond the pelvic region, with $38 \%$ reporting pain in more than three sites simultaneously. Those with broader pain distributions demonstrated significantly poorer scores on the other elements of the SPACE symptom cluster (Lai et al., 2017). Similar findings have been reported in the context of TMD (Slade et al., 2013) and FM (Cassisi et al., 2014). 


\subsubsection{Affect}

By definition, pain of all types is both a sensory phenomenon as well as an emotional one (IASP, 2015). This has been supported empirically using neuroimaging techniques, which show that chronic pain in particular is represented by cortical activations within emotional regions more so than in sensory regions (Apkarian, Bushnell, Treede, \& Zubieta, 2005). The three emotions that are most commonly associated with chronic pain are depressed mood, anxiety, and anger. These emotions are in turn associated with reduced pain thresholds, reduced pain tolerances, and increased reported pain intensity (van Middendorp, Lumley, Jacobs, Bijlsma, \& Geenen, 2010; Tang et al., 2008; Wagner, Koschke, Leuf, Schlosser, \& Bar, 2009). Depressed affect can be assessed using a variety of instruments including the Beck Depression Inventory-II (BDI-II; (Beck, Steer, Ball, \& Ranieri, 1996; Beck, Steer, \& Garbin, 1988), the Center for Epidemiological Studies Depression Scale (CESD, CESD-R; (Eaton, Muntaner, Smith, Tien, \& Ybarra, 2004; Radloff, 1977)), or the Patient Health Questionnaire 9 (PHQ-9) (Kroenke, Spitzer, \& Williams, 2001)). Two measures of anxiety include the State-Trait Anxiety Inventory (STAI; (Spielberger, Gorsuch, Lushene, \& Vagg, 1983)) or the General Anxiety Disorder-7 (GAD-7; (Spitzer, Kroenke, Williams, \& Lowe, 2006)). Some measures, such as the Hospital Anxiety and Depression Scale (HADS; (Snaith, 2003)), assess both constructs. Scoring of these instruments can reveal either a probable diagnosis of an affective disorder or a continuous measure of negative affect. Other measures of negative affect (i.e., not diagnostic of disorders) include the PROMIS negative emotions scales (e.g., depressed affect, anxious affect, and anger) (Cella et al., 2010) and the Positive and Negative Affect Scale (PANAS; (Watson, Clark, \& Tellegen, 1988)). Currently more studies are needed to identify if there are unique affective characteristics that differentiate COPCs (and by implication CS) from other forms of chronic pain. As mentioned previously, the study of UCPPS patients demonstrated that greater widespreadedness of pain was associated with worse depressive and anxiety symptoms (as measured by the HADS) and worse mental health overall (as measured by the SF12) for both males and females (Lai et al., 2017).

\subsection{4 | Cognition}

Perhaps one of the most under-assessed symptoms in the S.P.A.C.E. cluster is cognition. In an exercise to identify relevant assessment domains for fibromyalgia, the Outcome Measures in Rheumatology clinical Trials network (OMERACT) conducted two Delphi studies; one with providers and one with patients. While there was agreement between the groups as to the importance of including symptoms such as pain, fatigue, and sleep, the patients rated cognitive problems as being far more important than did clinicians (Arnold et al., 2008; Mease et al., 2005, 2008).

To assess perceived cognitive difficulties across several dimensions, the Multiple Ability Self-Report Questionnaire (MASQ; (Seidenberg, Haltiner, Taylor, Hermann, \& Wyler, 1994)) has been used with FM samples (Williams \& Arnold, 2011; Williams, Clauw, \& Glass, 2011) and is able to capture perceived cognitive difficulties across language ability, visual-perceptual ability, verbal memory, visual memory, and attention/concentration. A second shorter measure, using items from the NIH PROMIS item banks is called the Multidimensional Inventory of Subjective Cognitive Impairment (MISCl; (Kratz, Schilling, Goesling, \& Williams, 2015)). This 10-item inventory, which provides indices for cognitive concerns in the areas of mental clarity, memory, attention/concentration, executive functioning, and language, is highly correlated $(r=0.82)$ with the lengthier MASQ, and was validated on a sample of FM patients.

\subsection{5 | Energy}

Fatigue may be as concerning to patients as pain and has become a research priority in painful conditions, including IBS (Lackner, Gudleski, Dimuro, Keefer, \& Brenner, 2013), TMS (Robinson, Durham, \& Newton, 2016), FM (Dailey, Keffala, \& Sluka, 2015), and migraine (Lau, Lin, Chen, Wang, \& Kao, 2015). The assessment of fatigue 
is challenging, given the need to distinguish qualitative aspects of the experience of fatigue; that is, to differentiate normal tiredness that might follow energy exertion from the more profound existential weariness that is described by individuals with COPCs (Humphrey et al., 2010). It can also be important to differentiate the experience of fatigue from the impact of fatigue (e.g., too fatigued to work, too fatigued to participate in activities of daily living etc.). One measure that nicely differentiates the experience of fatigue from its impact is the Multidimensional Fatigue Inventory (MFI; (Smets, Garssen, Bonke, \& De Haes, 1995)). The latter instrument allows for the assessment of general fatigue, physical fatigue, mental fatigue, reduced motivation, and reduced activity. PROMIS also offers brief assessments of fatigue experience and interference/impact (Cella et al., 2010). Based upon the PROMIS item banks, a Fatigue Profile has been developed that was specifically validated with a group of individuals with FM (Kratz, Schilling, Goesling, \& Williams, 2016).

\subsection{Associated domains of assessment}

Two additional domains of assessment that may have relevance to CS are perceived stress and early life trauma. Nijs et al. (2014) highlighted the importance of hypersensitivity of senses that are unrelated to the musculoskeletal system. Included in the list of drivers of hypersensitivity are stress and the concept of mental load. When sensory stimuli ascend from the periphery, they must be evaluated by the current state of the CNS, which can include stress and negative aspects of mental load. Stress is a state-like phenomenon with influences on pain perception and other elements of CS and can be assessed with measures such as the Perceived Stress Scale (PSS; (Cohen, Kamarck, \& Mermelstein, 1983)). More enduring stressful events, such as early life trauma, can influence affect and mental load in a trait-like manner. A variety of early life traumas (e.g., prolonged medical illness, loss of a parent, abuse etc.), and whether or not such traumatic events were disclosed to anyone, can be assessed using the Childhood and Recent Traumatic Events Scales (CTES/RTES; (Pennebaker \& Susman, 1988)) as a contributor to mental load.

\subsection{Existing and future measures of CS and COPCs}

The Central Sensitization Inventory (CSI; Neblett et al., 2013) was developed for the expressed purpose of assessing CS-related symptoms and has been mentioned frequently throughout this special issue. The CSI efficiently captures many of the domains covered in this article that are conceptually related to CS. For example, the CSI includes items associated with medical symptoms such as sleep problems, stress (mental load), pain, emotionality, concentration/memory, fatigue, and limited physical functioning. The CSI also includes items associated with general sensory hypersensitivity (e.g., sensitivity to bright lights and olfactory stimuli). The CSI is one assessment component of the clinical diagnostic algorithm by Nijs et al. (2014), mentioned earlier in this article, for identifying CS-related pain. While conceptually strong, future instruments may want to demonstrate stronger empirical relationships between self-reported items and QST, neuroimaging markers of CS, and S.P.A.C.E. Such a prospective measure (i.e., the Central Pain Index (CPI)) is currently in development (NIH/ NIAMS funding (AR070600)).

The modified ACR 2010 diagnostic criteria for FM can also be used as a proxy for assessing CS or centrally augmented pain (Wolfe et al., 2016). When scored as a continuous measure rather than a dichotomous diagnosis, the Poly-Symptomatic Distress score (PSD) appears to capture important elements of CS. The PSD is composed of an index of widespread pain, and each of the other elements of the S.P.A.C.E. symptom cluster. One might predict that peripherally driven interventions (e.g., surgery) would be less successful in individuals where CS is driving the pain experience. Such a hypothesis is supported by several studies, where higher scores on the PSD scale were associated with greater need for opioids and poorer outcomes following knee and hip arthroplasty and hysterectomy (As-Sanie et al., 2017; Brummett et al., 2015; Janda et al., 2015). 
TAB LE 2 CS Domains and sample self-reported assessment tools

\begin{tabular}{|c|c|c|}
\hline Domain and instruments & Purpose & References \\
\hline $\begin{array}{l}\text { Chronic overlapping pain } \\
\text { conditions }\end{array}$ & $\begin{array}{l}\text { Diagnostic entities with CS being the } \\
\text { suspected pathophysiological } \\
\text { mechanism }\end{array}$ & \\
\hline CMSI & Assesses a subset of the $10 \mathrm{COPCs}$ & (Williams \& Schilling, 2009) \\
\hline COPCS & Assesses all 10 COPCS & $\begin{array}{l}\text { (still in beta version as of this } \\
\text { publication) }\end{array}$ \\
\hline \multicolumn{3}{|l|}{ General hypersensitivity } \\
\hline SHS & $\begin{array}{l}\text { Assesses general and specific sensory } \\
\text { hypersensitivity }\end{array}$ & (Dixon et al., 2016) \\
\hline \multicolumn{3}{|l|}{ S.P.A.C.E. Symptom cluster } \\
\hline MOS sleep scale & Sleep problems & (Allen et al., 2009) \\
\hline PSQI & Sleep problems & (Buysse et al., 1989) \\
\hline PROMIS sleep disturbance & Sleep problems & (Yu et al., 2011) \\
\hline $\begin{array}{l}\text { PROMIS sleep-related } \\
\text { impairment }\end{array}$ & Nonrestorative sleep & (Yu et al., 2011) \\
\hline VAS, NRS & Pain intensity & (Jensen \& Karoly, 2011) \\
\hline$M P Q$ & Pain quality and intensity & (Melzack, 1987) \\
\hline $\mathrm{BPI}$ & Pain distribution and intensity & (Cleeland, 2009) \\
\hline Pain detect & $\begin{array}{l}\text { Pain distribution, intensity quality: } \\
\text { differentiate nociceptive from } \\
\text { neuropathic }\end{array}$ & $\begin{array}{l}\text { (Freynhagen, Baron, Gockel, \& Tolle, } \\
\text { 2006) }\end{array}$ \\
\hline BDI-II & Depressive symptomatology & (Beck et al., 1996) \\
\hline CESD-R & Depressive symptomatology & (Eaton et al., 2004) \\
\hline PHQ-9 & Depressive symptomatology & (Kroenke et al., 2001) \\
\hline STAI & Anxiety symptoms & (Spielberger et al., 1983) \\
\hline GAD-7 & Anxiety symptoms & (Spitzer et al., 2006) \\
\hline HADS & Both anxiety and depressive symptoms & (Snaith, 2003) \\
\hline PANAS & Positive and negative affect & (Watson et al., 1988) \\
\hline PROMIS Negative Emotions & Negative emotions & (Cella et al., 2010) \\
\hline MASQ & Perceived cognitive difficulties & (Seidenberg et al., 1994) \\
\hline $\mathrm{MISCl}$ & Perceived cognitive difficulties & (Kratz et al., 2015) \\
\hline MFI & Fatigue experience & (Smets et al., 1995) \\
\hline PROMIS Fatigue & Fatigue experience and impact & (Cella et al., 2010) \\
\hline Fatigue profile & Fatigue experience and impact & (Kratz et al., 2016) \\
\hline
\end{tabular}

Another way of assessing CS indirectly is by identifying the presence of COPCs. Until recently, there were no diagnostic tools that could capture the presence of all 10 COPCs using established diagnostic criteria. The $\mathrm{NIH}$ Pain Consortium has recently championed the development of such a tool using funding with the Office of Research on Women's Health, the Multidisciplinary Approach to the Study of Chronic Pelvic Pain (MAPP) and the Orofacial Pain: Prospective Evaluation and Risk Assessment (OPPERA) research networks. This new instrument, the "COPC Screener", will be made publically available and will be able to serve as a standardized way of assessing individuals suspected of having conditions where CS is the suspected pathophysiologic mechanism. 
TABLE 2 (Continued)

\begin{tabular}{|lll}
\hline $\begin{array}{l}\text { Domain and instruments } \\
\text { Supplemental domains }\end{array}$ & Purpose & References \\
\hline PSS & & (Cohen et al., 1983) \\
\hline CTES/RTES & Perceived stress & (Pennebaker \& Susman, 1988) \\
Comprehensive CS instruments & Early and recent trauma & \\
\hline CSI & Multiple components of CS & (Neblett et al., 2013) \\
\hline Modified fm criteria & Multiple components of central pain & (Wolfe et al., 2016) \\
\hline
\end{tabular}

Note. CMSI, Complex Medical Symptom Inventory; COPCS, Chronic Overlapping Pain Conditions Screener; SHS, Sensory Hypersensitivity Scale; MOS sleep Scale, Medical Outcomes Survey Sleep Scale; PSQI, Pittsburgh Sleep Quality Index; PROMIS Sleep Disturbance Scale; PROMIS Sleep-related impairment scale; VAS, Visual Analog Scale; NRS, Numeric Rating Scale; MPQ, McGill Pain Questionnaire ; BPI, Brief Pain Inventory; Pain Detect; BDI-II, Beck Depression Scale-II; CESD-R, Center for Epidemiologic Studies Depression Scale; PHQ-9, Patient Health Questionnaire 9-item Scale; STAI, State-Trait Anxiety Inventory; GAD-7, General Anxiety Disorder 7-item Scale; HADS, Hospital Anxiety and Depression Scale; PANAS, Positive and Negative Affect Scale; PROMIS Negative Emotions Scale; MASQ, Multiple Abilities Symptom Questionnaire; $\mathrm{MISCl}$, Multidimensional Inventory of Subjective Cognitive Impairment; MFI, Multidimensional Fatigue Inventory; PSS, PROMIS Fatigue Scale; Fatigue Profile; Perceived Stress Scale; CTES/RTES, Childhood/Recent Traumatic Events Scale; CSI, Central Sensitization Index; Modified ACR2010 FM diagnostic Criteria.

\section{4 | CONCLUSION}

Central sensitization likely underlies how normal sensory or mild nociceptive stimuli can be amplified by the CNS to produce a profound and prolonged pain experience. Clinically COPCs are the best representations of conditions having CS as a primary mechanism. To comprehensively phenotype the facets of CS in a clinical sample, a combination of QST, to identify multisensory hypersensitivity, and patient-reported outcomes of the S.P.A.C.E. symptom cluster (i.e., "unwellness") can be used (see Table 2). In addition, multicomponent self-report instruments such as the CSI or FM diagnostic criteria are efficient clinical tools for indexing CS comprehensively.

\section{CONFLICT OF INTEREST}

Dr. Williams serves as a consultant to Community Health Focus Inc. He is currently the Immediate Past President of the American Pain Society. There is no conflict associated with the content or preparation of this manuscript.

\section{ORCID}

David A. Williams iD http://orcid.org/0000-0002-5052-4895

\section{REFERENCES}

Aktas, A., Walsh, D., \& Rybicki, L. (2010). Symptom clusters: Myth or reality? Palliative Medicine, 24(4), 373-385. https:// doi.org/10.1177/0269216310367842

Allen, R. P., Kosinski, M., Hill-Zabala, C. E., \& Calloway, M. O. (2009). Psychometric evaluation and tests of validity of the Medical Outcomes Study 12-item Sleep Scale (MOS sleep). Sleep Medicine, 10(5), 531-539. https://doi.org/10.1016/j. sleep.2008.06.003

Apkarian, A. V., Bushnell, M. C., Treede, R. D., \& Zubieta, J. K. (2005). Human brain mechanisms of pain perception and regulation in health and disease. European Journal of Pain, 9(4), 463-484.

Arnold, L. M., Crofford, L. J., Mease, P. J., Burgess, S. M., Palmer, S. C., Abetz, L., \& Martin, S. A. (2008). Patient perspectives on the impact of fibromyalgia. Patient Education and Counseling, 73, 114-120. 
As-Sanie, S., Till, S. R., Mowers, E. L., Lim, C. S., Skinner, B. D., Fritsch, L., ... Brummett, C. M. (2017). Opioid prescribing patterns, patient use, and postoperative pain after hysterectomy for benign indications. Obstetrics and Gynecology, 130, 1261-1268. https://doi.org/10.1097/aog.0000000000002344

Audrain-McGovern, J., Nigg, J. T., \& Perkins, K. A. (2009). Endophenotypes for nicatine-dependence risk at or before initial nicotine exposure. (20). Bethesda, MA: National Cancer Institute.

Beauchaine, T. P., \& Constantino, J. N. (2017). Redefining the endophenotype concept to accommodate transdiagnostic vulnerabilities and etiological complexity. Biomarkers in Medicine, 11, 769-780https://doi.org/10.2217/ bmm-2017-0002

Beck, A. T., Steer, R. A., Ball, R., \& Ranieri, W. F. (1996). Comparison of beck depression inventories-IA and -II in psychiatric outpatients. Journal of Personality Assessment, 67(3), 588-597. https://doi.org/DOI 10.1207/s15327752jpa6703_13

Beck, A. T., Steer, R. A., \& Garbin, M. G. (1988). Psychometric properties of the Beck Depression Inventory: Twenty-five years of evaluation. Clinical Psychology Review, 8, 77-100.

Berkley, K. J., Cason, A., Jacobs, H., Bradshaw, H., \& Wood, E. (2001). Vaginal hyperalgesia in a rat model of endometriosis. Neuroscience Letters, 306(3), 185-188.

Berman, S. M., Naliboff, B. D., Chang, L., Fitzgerald, L., Antolin, T., Camplone, A., \& Mayer, E. A. (2002). Enhanced preattentive central nervous system reactivity in irritable bowel syndrome. American Journal of Gastroenterology, 97(11), 2791-2797. https://doi.org/10.1111/j.1572-0241.2002.07024.x

Blomhoff, S., Jacobsen, M. B., Spetalen, S., Dahm, A., \& Malt, U. F. (2000). Perceptual hyperreactivity to auditory stimuli in patients with irritable bowel syndrome. Scandinavian Journal of Gastroenterology, 35(6), 583-589.

Brummett, C. M., Urquhart, A. G., Hassett, A. L., Tsodikov, A., Hallstrom, B. R., Wood, N. I., ... Clauw, D. J. (2015). Characteristics of fibromyalgia independently predict poorer long-term analgesic outcomes following total knee and hip arthroplasty. Arthritis and Rheumatology, 67(5), 1386-1394. https://doi.org/10.1002/art.39051

Buysse, D. J., Reynolds, C. F. III, Monk, T. H., Berman, S. R., \& Kupfer, D. J. (1989). The Pittsburgh Sleep Quality Index: A new instrument for psychiatric practice and research. Psychiatry Research, 28(2), 193-213.

Calhoun, A. H., Ford, S., Finkel, A. G., Kahn, K. A., \& Mann, J. D. (2006). The prevalence and spectrum of sleep problems in women with transformed migraine. Headache, 46(4), 604-610. https://doi. $\operatorname{org} / 10.1111 /$ j.1526-4610.2006.00410.x

Cassisi, G., Sarzi-Puttini, P., Casale, R., Cazzola, M., Boccassini, L., Atzeni, F., \& Stisi, S. (2014). Pain in fibromyalgia and related conditions. Reumatismo, 66(1), 72-86. https://doi.org/10.4081/reumatismo.2014.767

Cella, D., Riley, W., Stone, A., Rothrock, N., Reeve, B., Yount, S., ... Hays, R. (2010). The Patient-Reported Outcomes Measurement Information System (PROMIS) developed and tested its first wave of adult self-reported health outcome item banks: 2005-2008. Journal of Clinical Epidemiology, 63(11), 1179-1194. https://doi.org/10.1016/j. jclinepi.2010.04.011

Chaves, T. C., Dach, F., Florencio, L. L., Carvalho, G. F., Goncalves, M. C., Bigal, M. E., ... Bevilaqua-Grossi, D. (2016). Concomitant migraine and temporomandibular disorders are associated with higher heat pain hyperalgesia and cephalic cutaneous allodynia. Clinical Journal of Pain, 32(10), 882-888. https://doi.org/10.1097/AJP.0000000000000369

Choy, E. H. (2015). The role of sleep in pain and fibromyalgia. Nature Reviews Rheumatology, 11(9), 513-520. https://doi. org/10.1038/nrrheum.2015.56

Clauw, D. J. (2014). Fibromyalgia: A clinical review. JAMA, 311(15), 1547-1555. https://doi.org/10.1001/ jama.2014.3266

Cleeland, C. (2009). The brief pain inventory: User guide. Houston, TX: MD Anderson Cancer Center.

Cleeland, C. S., Bennett, G. J., Dantzer, R., Dougherty, P. M., Dunn, A. J., Meyers, C. A., ... Lee, B. N. (2003). Are the symptoms of cancer and cancer treatment due to a shared biologic mechanism? A cytokine-immunologic model of cancer symptoms. Cancer, 97(11), 2919-2925. https://doi.org/10.1002/cncr.11382

Cohen, S., Kamarck, T., \& Mermelstein, R. (1983). A global measure of perceived stress. Journal of Health and Social Behavior, 24(4), 385-396.

Committee on Advancing Pain Research, C., Education, \& Institute of, M. (2011). Relieving pain in America: A blueprint for transforming prevention, care, education, and research. Washington, DC: The National Academies Press.

Crettaz, B., Marziniak, M., Willeke, P., Young, P., Hellhammer, D., Stumpf, A., \& Burgmer, M. (2013). Stress-induced allodynia-evidence of increased pain sensitivity in healthy humans and patients with chronic pain after experimentally induced psychosocial stress. PLoS ONE, 8(8), e69460. https://doi.org/10.1371/journal.pone.0069460

Dailey, D. L., Keffala, V. J., \& Sluka, K. A. (2015). Do cognitive and physical fatigue tasks enhance pain, cognitive fatigue, and physical fatigue in people with fibromyalgia? Arthritis Care and Research, 67(2), 288-296. https://doi.org/10.1002/ acr. 22417

Davis, L. L., Kroenke, K., Monahan, P., Kean, J., \& Stump, T. E. (2016). The SPADE symptom cluster in primary care patients with chronic pain. Clinical Journal of Pain, 32(5), 388-393. https://doi.org/10.1097/AJP.0000000000000286

Diatchenko, L., Nackley, A. G., Slade, G. D., Fillingim, R. B., \& Maixner, W. (2006). Idiopathic pain disorders-pathways of vulnerability. Pain, 123(3), 226-230. 
Dixon, E. A., Benham, G., Sturgeon, J. A., Mackey, S., Johnson, K. A., \& Younger, J. (2016). Development of the Sensory Hypersensitivity Scale (SHS): A self-report tool for assessing sensitivity to sensory stimuli. Journal of Behavioral Medicine, 39(3), 537-550. https://doi.org/10.1007/s10865-016-9720-3

Dodd, M. J., Miaskowski, C., \& Paul, S. M. (2001). Symptom clusters and their effect on the functional status of patients with cancer. Oncology Nursing Forum, 28(3), 465-470.

Eaton, W. W., Muntaner, C., Smith, C., Tien, A., \& Ybarra, M. (2004). Center for Epidemiologic Studies Depression Scale: Review and revision (CESD and CESD-R). In M. E. Maruish (Ed.), The Use of Psychological Testing for Treatment Planning and Outcomes Assessment, 3rd ed. (pp. 363-377). Mahwah, NH: Lawrence Erlbaum.

Eken, A., Gokcay, D., Yilmaz, C., Baskak, B., Baltaci, A., \& Kara, M. (2017). Association of fine motor loss and allodynia in fibromyalgia: An fNIRS study. Journal of Motor Behavior, 1-13. https://doi.org/10.1080/00222895.2017.1400947

Ernberg, M., Hedenberg-Magnusson, B., Alstergren, P., Lundeberg, T., \& Kopp, S. (1999). Pain, allodynia, and serum serotonin level in orofacial pain of muscular origin. Journal of Orofacial Pain, 13(1), 56-62.

Freynhagen, R., Baron, R., Gockel, U., \& Tolle, T. R. (2006). painDETECT: A new screening questionnaire to identify neuropathic components in patients with back pain. Current Medical Research and Opinion, 22(10), 1911-1920. https://doi. org/10.1185/030079906X132488

Friedman, D. I., \& De ver Dye, T. (2009). Migraine and the environment. Headache, 49(6), 941-952. https://doi. org/10.1111/j.1526-4610.2009.01443.x

Geisser, M. E., Glass, J. M., Rajcevska, L. D., Clauw, D. J., Williams, D. A., Kileny, P. R., \& Gracely, R. H. (2008). A psychophysical study of auditory and pressure sensitivity in patients with fibromyalgia and healthy controls. Journal of Pain, 9(5), 417-422.

Goadsby, P. J., Holland, P. R., Martins-Oliveira, M., Hoffmann, J., Schankin, C., \& Akerman, S. (2017). Pathophysiology of migraine: A disorder of sensory processing. Physiological Reviews, 97(2), 553-622. https://doi.org/10.1152/ physrev.00034.2015

Gottesman, I. I., \& Gould, T. D. (2003). The endophenotype concept in psychiatry: Etymology and strategic intentions. American Journal of Psychiatry, 160(4), 636-645. https://doi.org/10.1176/appi.ajp.160.4.636

Hall, M. H., \& Smoller, J. W. (2010). A new role for endophenotypes in the GWAS era: Functional characterization of risk variants. Harvard Review of Psychiatry, 18(1), 67-74. https://doi.org/10.3109/10673220903523532

Harte, S. E., Ichesco, E., Hampson, J. P., Peltier, S. J., Schmidt-Wilcke, T., Clauw, D. J., \& Harris, R. E. (2016). Pharmacologic attenuation of cross-modal sensory augmentation within the chronic pain insula. Pain, 157(9), 1933-1945. https://doi. org/10.1097/j.pain.0000000000000593

Harte, S. E., Mitra, M., Ichesco, E. A., Halvorson, M. E., Clauw, D. J., Shih, A. J., \& Kruger, G. H. (2013). Development and validation of a pressure-type automated quantitative sensory testing system for point-of-care pain assessment. Medical and Biological Engineering and Computing, 51(6), 633-644. https://doi.org/10.1007/s11517-013-1033-x

Henry, N. L., Conlon, A., Kidwell, K. M., Griffith, K., Smerage, J. B., Schott, A. F., ... Harte, S. E. (2014). Effect of estrogen depletion on pain sensitivity in aromatase inhibitor-treated women with early-stage breast cancer. Journal of Pain, 15(5), 468-475. https://doi.org/10.1016/j.jpain.2014.01.487

Hollins, M., Harper, D., Gallagher, S., Owings, E. W., Lim, P. F., Miller, V., ... Maixner, W. (2009). Perceived intensity and unpleasantness of cutaneous and auditory stimuli: An evaluation of the generalized hypervigilance hypothesis. Pain, 141(3), 215-221. https://doi.org/10.1016/j.pain.2008.10.003

Humphrey, L., Arbuckle, R., Mease, P., Williams, D. A., Samsoe, B. D., \& Gilbert, C. (2010). Fatigue in fibromyalgia: A conceptual model informed by patient interviews. BMC Musculoskeletal Disorders, 11, 216. https://doi. org/10.1186/1471-2474-11-216

lannetti, G. D., \& Mouraux, A. (2010). From the neuromatrix to the pain matrix (and back). Experimental Brain Research, 205(1), 1-12. https://doi.org/10.1007/s00221-010-2340-1

IASP (2015). IASP Taxonomy. Retrieved from www.IASP-Pain.org/taxonomy

Janda, A. M., As-Sanie, S., Rajala, B., Tsodikov, A., Moser, S. E., Clauw, D. J., \& Brummett, C. M. (2015). Fibromyalgia survey criteria is associated with increased postoperative opioid consumption in women undergoing hysterectomy. Anesthesiology, https://doi.org/10.1097/ALN.0000000000000637

Janig, W. (2015). Pain, hyperalgesia and stress. European Journal of Pain, 19(6), 741-742. https://doi.org/10.1002/ejp.701

Jayaram, A., Esbrand, F., Dulaveris, G., Orfanelli, T., Sobel, R., Ledger, W. J., \& Witkin, S. S. (2015). Decreased concentration of protease inhibitors: Possible contributors to allodynia and hyperalgesia in women with vestibulodynia. American Journal of Obstetrics and Gynecology, 212(2), 184. e181-184. https://doi.org/10.1016/j.ajog.2014.07.029

Jensen, M. P., \& Karoly, P. (2011). Self-report scales and procedures for assessing pain in adults. In D. C. Turk, \& R. Melzack (Eds.), Handbook of Pain Assessment (pp. 19-44). New York, NY: Guilford Press.

Kratz, A. L., Murphy, S. L., \& Braley, T. J. (2017). Pain, fatigue, and cognitive symptoms are temporally associated within but not across days in multiple sclerosis. Archives of Physical Medicine and Rehabilitation, 98(11), 2151-2159. https:// doi.org/10.1016/j.apmr.2017.07.003 
Kratz, A. L., Schilling, S. G., Goesling, J., \& Williams, D. A. (2015). Development and initial validation of a brief selfreport measure of cognitive dysfunction in fibromyalgia. Journal of Pain, 16(6), 527-536. https://doi.org/10.1016/j. jpain.2015.02.008

Kratz, A. L., Schilling, S., Goesling, J., \& Williams, D. A. (2016). The PROMIS Fatigue Profile: A self-report measure of fatigue for use in fibromyalgia. Quality of Life Research, https://doi.org/10.1007/s11136-016-1230-9

Kroenke, K., Spitzer, R. L., \& Williams, J. B. (2001). The PHQ-9: Validity of a brief depression severity measure. Journal of General Internal Medicine, 16(9), 606-613.

Lackner, J. M., Gudleski, G. D., Dimuro, J., Keefer, L., \& Brenner, D. M. (2013). Psychosocial predictors of self-reported fatigue in patients with moderate to severe irritable bowel syndrome. Behavior Research and Therapy, 51(6), 323-331. https://doi.org/10.1016/j.brat.2013.03.001

Lai, H. H., Jemielita, T., Sutcliffe, S., Bradley, C. S., Naliboff, B., Williams, D. A., ... Network, M. R. (2017). Characterization of whole body pain in urological chronic pelvic pain syndrome at baseline: A MAPP research network study. Journal of Urology, 198(3), 622-631. https://doi.org/10.1016/j.juro.2017.03.132

Latremoliere, A., \& Woolf, C. J. (2009). Central sensitization: A generator of pain hypersensitivity by central neural plasticity. Journal of Pain, 10(9), 895-926. https://doi.org/10.1016/j.jpain.2009.06.012

Lau, C. I., Lin, C. C., Chen, W. H., Wang, H. C., \& Kao, C. H. (2015). Increased risk of chronic fatigue syndrome in patients with migraine: A retrospective cohort study. Journal of Psychosomatic Research, 79(6), 514-518. https://doi. org/10.1016/j.jpsychores.2015.10.005

Leavitt, F., Katz, R. S., Golden, H. E., Glickman, P. B., \& Layfer, L. F. (1986). Comparison of pain properties in fibromyalgia patients and rheumatoid arthritis patients. Arthritis and Rheumatism, 29(6), 775-781.

Legrain, V., lannetti, G. D., Plaghki, L., \& Mouraux, A. (2011). The pain matrix reloaded: A salience detection system for the body. Progress in Neurobiology, 93(1), 111-124. https://doi.org/10.1016/j.pneurobio.2010.10.005

Low, L. A., \& Schweinhardt, P. (2012). Early life adversity as a risk factor for fibromyalgia in later life. Pain Research and Treatment, 2012, 140832. https://doi.org/10.1155/2012/140832

Main, A., Dowson, A., \& Gross, M. (1997). Photophobia and phonophobia in migraineurs between attacks. Headache, 37, 492-495.

Maixner, W., Fillingim, R., Sigurdsson, A., Kincaid, S., \& Silva, S. (1998). Sensitivity of patients with painful temporomandibular disorders to experimentally evoked pain: Evidence for altered temporal summation of pain. Pain, 76(1-2), 71-81.

Maixner, W., Fillingim, R. B., Williams, D. A., Smith, S. B., \& Slade, G. D. (2016). Overlapping chronic pain conditions: Implications for diagnosis and classification. Journal of Pain, 17(9 Suppl), T93-T107. https://doi.org/10.1016/j. jpain.2016.06.002

Maracle, E. C., Hung, L. Y., Fell, S. I., Osmond, M. R., Brown, S. H., \& Srbely, J. Z. (2017). A comparison of the sensitivity of brush allodynia and semmes-weinstein monofilament testing in the detection of allodynia within regions of secondary hyperalgesia in humans. Pain Practice, 17(1), 16-24. https://doi.org/10.1111/papr.12418

McAllister, S. L., McGinty, K. A., Resuehr, D., \& Berkley, K. J. (2009). Endometriosis-induced vaginal hyperalgesia in the rat: Role of the ectopic growths and their innervation. Pain, 147(1-3), 255-264. https://doi.org/10.1016/j. pain.2009.09.022

Mease, P. J., Arnold, L. M., Crofford, L. J., Williams, D. A., Russell, I. J., Humphrey, L., ... Martin, S. A. (2008). Identifying the clinical domains of fibromyalgia: Contributions from clinician and patient Delphi exercises. Arthritis and Rheumatism, 59(7), 952-960. https://doi.org/10.1002/art.23826

Mease, P. J., Clauw, D. J., Arnold, L. M., Goldenberg, D. L., Witter, J., Williams, D. A., ... Crofford, L. J. (2005). Fibromyalgia syndrome. Journal of Rheumatology, 32(11), 2270-2277.

Melzack, R. (1975). The McGill Pain Questionnaire: Major properties and scoring methods. Pain, 1(3), $277-299$.

Melzack, R. (1987). The short-form McGill pain questionnaire. Pain, 30(2), 191-197.

Miaskowski, C., Dodd, M., \& Lee, K. (2004). Symptom clusters: The new frontier in symptom management research. Journal of the National Cancer Institute Monographs, 32, 17-21. https://doi.org/10.1093/jncimonographs/lgh023

Napadow, V., Edwards, R. R., Cahalan, C. M., Mensing, G., Greenbaum, S., Valovska, A., ... Wasan, A. D. (2012). Evoked pain analgesia in chronic pelvic pain patients using respiratory-gated auricular vagal afferent nerve stimulation. Pain Medicine, 13(6), 777-789. https://doi.org/10.1111/j.1526-4637.2012.01385.x

Neblett, R., Cohen, H., Choi, Y., Hartzell, M. M., Williams, M., Mayer, T. G., \& Gatchel, R. J. (2013). The Central Sensitization Inventory (CSI): Establishing clinically significant values for identifying central sensitivity syndromes in an outpatient chronic pain sample. Journal of Pain, 14(5), 438-445. https://doi.org/10.1016/j.jpain.2012.11.012

Nijs, J., Torres-Cueco, R., van Wilgen, C. P., Girbes, E. L., Struyf, F., Roussel, N., ... Meeus, M. (2014). Applying modern pain neuroscience in clinical practice: Criteria for the classification of central sensitization pain. Pain Physician, 17(5), 447-457.

Pennebaker, J. W., \& Susman, J. R. (1988). Disclosure of traumas and psychosomatic processes. Social Science and Medicine, 26(3), 327-332. 
Price, D. D., Staud, R., Robinson, M. E., Mauderli, A. P., Cannon, R., \& Vierck, C. J. (2002). Enhanced temporal summation of second pain and its central modulation in fibromyalgia patients. Pain, 99(1-2), 49-59.

Pujol, J., Macia, D., Garcia-Fontanals, A., Blanco-Hinojo, L., Lopez-Sola, M., Garcia-Blanco, S., ... Deus, J. (2014). The contribution of sensory system functional connectivity reduction to clinical pain in fibromyalgia. Pain, 155(8), 14921503. https://doi.org/10.1016/j.pain.2014.04.028

Radloff, L. S. (1977). The CES-D Scale: A self-report depression scale for research in the general population. Applied Psychological Measurement, 1(3), 385-401.

Robinson, L. J., Durham, J., \& Newton, J. L. (2016). A systematic review of the comorbidity between Temporomandibular Disorders and Chronic Fatigue Syndrome. Journal of Oral Rehabilitation, 43(4), 306-316. https://doi.org/10.1111/ joor.12367

Rolke, R., Baron, R., Maier, C., Tolle, T. R., Treede, R. D., Beyer, A., ... Wasserka, B. (2006). Quantitative sensory testing in the German Research Network on Neuropathic Pain (DFNS): Standardized protocol and reference values. Pain, 123(3), 231-243. https://doi.org/10.1016/j.pain.2006.01.041

Scheich, B., Vincze, P., Szoke, E., Borbely, E., Hunyady, A., Szolcsanyi, J., ... Helyes, Z. (2017). Chronic stress-induced mechanical hyperalgesia is controlled by capsaicin-sensitive neurones in the mouse. European Journal of Pain, 21(8), 1417-1431. https://doi.org/10.1002/ejp.1043

Schmidt-Wilcke, T., Kairys, A., Ichesco, E., Fernandez-Sanchez, M. L., Barjola, P., Heitzeg, M., ... Williams, D. A. (2014). Changes in clinical pain in fibromyalgia patients correlate with changes in brain activation in the cingulate cortex in a response inhibition task. Pain Medicine, https://doi.org/10.1111/pme.12460

Schrepf, A., Bradley, C. S., O'Donnell, M., Luo, Y., Harte, S. E., Kreder, K., ... Multidisciplinary Approach to the Study of Chronic Pelvic Pain Research, N (2015). Toll-like Receptor 4 and comorbid pain in interstitial cystitis/bladder pain syndrome: A multidisciplinary approach to the study of chronic pelvic pain research network study. Brain Behavior and Immunity, 49, 66-74. https://doi.org/10.1016/j.bbi.2015.03.003

Seidenberg, M., Haltiner, A., Taylor, M. A., Hermann, B. B., \& Wyler, A. (1994). Development and validation of a Multiple Ability Self-Report Questionnaire. Journal of Clinical and Experimental Neuropsychology, 16(1), 93-104.

Shattuck, E. C., \& Muehlenbein, M. P. (2016). Towards an integrative picture of human sickness behavior. Brain Behavior and Immunity, 57, 255-262. https://doi.org/10.1016/j.bbi.2016.05.002

Slade, G. D., Smith, S. B., Zaykin, D. V., Tchivileva, I. E., Gibson, D. G., Yuryev, A., ... Diatchenko, L. (2013). Facial pain with localized and widespread manifestations: Separate pathways of vulnerability. Pain, 154(11), 2335-2343. https://doi. org/10.1016/j.pain.2013.07.009

Smets, E. M., Garssen, B., Bonke, B., \& De Haes, J. C. (1995). The Multidimensional Fatigue Inventory (MFI) psychometric qualities of an instrument to assess fatigue. Journal of Psychosomatic Research, 39(3), 315-325.

Snaith, R. P. (2003). The hospital anxiety and depression scale. Health and Quality of Life Outcomes, 1, 29. https://doi. org/10.1186/1477-7525-1-29

Spiegel, B. M., Bolus, R., Harris, L. A., Lucak, S., Chey, W. D., Sayuk, G., ... Chang, L. (2010). Characterizing abdominal pain in IBS: Guidance for study inclusion criteria, outcome measurement and clinical practice. Alimentary Pharmacology and Therapeutics, 32(9), 1192-1202. https://doi.org/10.1111/j.1365-2036.2010.04443.x

Spielberger, C. D., Gorsuch, R. C., Lushene, R. E., \& Vagg, P. R. (1983). Manual for the state-trait anxiety inventory (Form Y): ("Self-evaluation questionnaire"). Palo Alto, CA: Consulting Psychologists.

Spitzer, R. L., Kroenke, K., Williams, J. B., \& Lowe, B. (2006). A brief measure for assessing generalized anxiety disorder: The GAD-7. Archives of Internal Medicine, 166(10), 1092-1097. https://doi.org/10.1001/archinte.166.10.1092

Strimbu, K., \& Tavel, J. A. (2010). What are biomarkers? Current Opinion in HIV and AIDS, 5(6), 463-466. https://doi. org/10.1097/COH.0b013e32833ed177

Szatmari, P., Maziade, M., Zwaigenbaum, L., Merette, C., Roy, M. A., Joober, R., \& Palmour, R. (2007). Informative phenotypes for genetic studies of psychiatric disorders. American Journal of Medical Genetics, 144B(5), 581-588. https://doi. org/10.1002/ajmg.b.30426

Tang, N. K., Salkovskis, P. M., Hodges, A., Wright, K. J., Hanna, M., \& Hester, J. (2008). Effects of mood on pain responses and pain tolerance: An experimental study in chronic back pain patients. Pain, 138(2), 392-401. https://doi. org/10.1016/j.pain.2008.01.018

Tesarz, J., Eich, W., Treede, R. D., \& Gerhardt, A. (2016). Altered pressure pain thresholds and increased wind-up in adult patients with chronic back pain with a history of childhood maltreatment: A quantitative sensory testing study. Pain, 157(8), 1799-1809. https://doi.org/10.1097/j.pain.0000000000000586

Tietjen, G. E., Brandes, J. L., Peterlin, B. L., Eloff, A., Dafer, R. M., Stein, M. R., ... Khuder, S. A. (2009). Allodynia in migraine: Association with comorbid pain conditions. Headache, 49(9), 1333-1344. https://doi. org/10.1111/j.1526-4610.2009.01521.x

Tizard, I. (2008). Sickness behavior, its mechanisms and significance. Animal Health Research Reviews, 9(1), 87-99. https:// doi.org/10.1017/S1466252308001448 
Toriyama, T., Horiuchi, T., \& Hongo, K. (2017). Characterization of migraineurs presenting interictal widespread pressure hyperalgesia identified using a tender point count: A cross-sectional study. Journal of Headache Pain, $18(1), 117$. https://doi.org/10.1186/s10194-017-0824-0

Tsuang, M. T. (2001). Defining alternative phenotypes for genetic studies: What can we learn from studies of schizophrenia? American Journal of Medical Genetics, 105(1), 8-10.

Tu, Q., Heitkemper, M. M., Jarrett, M. E., \& Buchanan, D. T. (2017). Sleep disturbances in irritable bowel syndrome: A systematic review. Neurogastroenterology and Motility, 29(3), https://doi.org/10.1111/nmo.12946

van Middendorp, H., Lumley, M. A., Jacobs, J. W., Bijlsma, J. W., \& Geenen, R. (2010). The effects of anger and sadness on clinical pain reports and experimentally-induced pain thresholds in women with and without fibromyalgia. Arthritis Care and Research, 62(10), 1370-1376. https://doi.org/10.1002/acr.20230

Veasley, C., Clare, D., Clauw, D. J., Cowley, T., Nguyen, R. H., \& Reinecke, P., (2015). Impact of chronic overlapping pain conditions on public health and the urgent need for safe and effective treatment: 2015 analysis and policy recommendations.

Wagner, G., Koschke, M., Leuf, T., Schlosser, R., \& Bar, K. J. (2009). Reduced heat pain thresholds after sad-mood induction are associated with changes in thalamic activity. Neuropsychologia, 47(4), 980-987. https://doi.org/DOI 10.1016/j.neuropsychologia.2008.10.021

Wasserman, R. A., Hassett, A. L., Harte, S. E., Goesling, J., Malinoff, H. L., Berland, D. W., ... Brummett, C. M. (2015). Pressure pain sensitivity in patients with suspected opioid-induced hyperalgesia. Regional Anesthesia and Pain Medicine, 40(6), 687-693. https://doi.org/10.1097/AAP.0000000000000315

Watson, D., Clark, L. A., \& Tellegen, A. (1988). Development and validation of brief measures of positive and negative affect: The PANAS scales. Journal of Personality and Social Psychology, 54(6), 1063-1070.

Wilbarger, J. L., \& Cook, D. B. (2011). Multisensory hypersensitivity in women with fibromyalgia: Implications for well being and intervention. Archives of Physical Medicine and Rehabilitation, 92(4), 653-656. https://doi.org/10.1016/j. apmr.2010.10.029

Williams, D. A., \& Arnold, L. M. (2011). Measures of fibromyalgia: Fibromyalgia Impact Questionnaire (FIQ), Brief Pain Inventory (BPI), Multidimensional Fatigue Inventory (MFI-20), Medical Outcomes Study (MOS) Sleep Scale, and Multiple Ability Self-Report Questionnaire (MASQ). Arthritis Care and Research, 63(Suppl. 11), S86-S97. https://doi. org/10.1002/acr.20531

Williams, D. A., \& Clauw, D. J. (2009). Understanding fibromyalgia: Lessons from the broader pain research community. Journal of Pain, 10(8), 777-791. https://doi.org/10.1016/j.jpain.2009.06.001

Williams, D. A., Clauw, D. J., \& Glass, J. M. (2011). Perceived cognitive dysfunction in fibromyalgia syndrome. Journal of Musculoskeletal Pain, 19(2), 66-75.

Williams, D. A., \& Schilling, S. (2009). Advances in the assessment of fibromyalgia. Rheumatic Diseases Clinics of North America, 35(2), 339-357. https://doi.org/10.1016/j.rdc.2009.05.007

Wolfe, F., Clauw, D. J., Fitzcharles, M. A., Goldenberg, D. L., Hauser, W., Katz, R. L., ... Walitt, B. (2016). 2016 Revisions to the 2010/2011 fibromyalgia diagnostic criteria. Seminars in Arthritis and Rheumatism, 46(3), 319-329. https://doi. org/10.1016/j.semarthrit.2016.08.012

Wolfe, F., Clauw, D. J., Fitzcharles, M. A., Goldenberg, D. L., Katz, R. S., Mease, P., ... Yunus, M. B. (2010). The American College of Rheumatology preliminary diagnostic criteria for fibromyalgia and measurement of symptom severity. Arthritis Care and Research, 62(5), 600-610. https://doi.org/10.1002/acr.20140

Woolf, C. J. (2011). Central sensitization: Implications for the diagnosis and treatment of pain. Pain, 152(3 Suppl), S2-S15. https://doi.org/10.1016/j.pain.2010.09.030

Yasui, M., Yoshimura, T., Takeuchi, S., Tokizane, K., Tsuda, M., Inoue, K., \& Kiyama, H. (2014). A chronic fatigue syndrome model demonstrates mechanical allodynia and muscular hyperalgesia via spinal microglial activation. Glia, 62(9), 1407-1417. https://doi.org/10.1002/glia.22687

Yu, L., Buysse, D. J., Germain, A., Moul, D. E., Stover, A., Dodds, N. E., ... Pilkonis, P. A. (2011). Development of short forms from the PROMIS sleep disturbance and Sleep-Related Impairment item banks. Behavioral Sleep Medicine, 10(1), 6-24. https://doi.org/10.1080/15402002.2012.636266

Zhou, Q., Price, D. D., Callam, C. S., Woodruff, M. A., \& Verne, G. N. (2011). Effects of the N-methyl-D-aspartate receptor on temporal summation of second pain (wind-up) in irritable bowel syndrome. Journal of Pain, 12(2), 297-303. https:// doi.org/10.1016/j.jpain.2010.09.002

How to cite this article: Williams DA. Phenotypic features of central sensitization. J Appl Behav Res. 2018;23:e12135. https://doi.org/10.1111/jabr.12135 